\title{
DIÁLOGOS SOBRE O CONHECIMENTO MATEMÁTICO DE UM GRUPO DE PROFESSORES DE MATEMÁTICA EM FORMAÇÃO INICIAL
}

\section{DIALOGUES ON THE MATHEMATICAL KNOWLEDGE OF A GROUP OF PRE-SERVICE MATHEMATICS TEACHERS}

\author{
DIÁLOGOS SOBRE EL CONOCIMIENTO MATEMÁTICO DE UN GRUPO DE \\ PROFESORES DE MATEMÁTICAS EN FORMACIÓN INICIAL
}

\author{
Mayline Regina Silva * (D) 0 \\ Wellington Lima Cedro ${ }^{* *}$ (D) $(9$
}

\begin{abstract}
RESUMO
O presente artigo tem como objetivo discutir aspectos da coletividade como unidade pedagógica na formação inicial do professor de matemática, em um processo de significação do conhecimento, pelos pressupostos da Teoria Histórico-Cultural. Compreendendo que a atividade coletiva está relacionada tanto aos processos de construção do conhecimento científico sistematizado e organizado pela escola, quanto nos processos de apropriação da cultura. Com isso, apresentamos, neste texto, reflexões acerca da coletividade na formação inicial de professores de matemática e uma síntese acerca da investigação realizada, por meio de ações formativas que desenvolvidas durante um ano letivo com um grupo de estudantes da Licenciatura em Matemática. A análise foi realizada por meio do método Materialista Histórico-Dialético, o que nos direcionou para a compreensão das unidades de análise: do movimento da história do conhecimento matemático; da busca pelo compartilhamento de significados; dos conflitos que mobilizam e transformam os sentidos por meio das experiências vivenciadas com o outro e a humanização do conhecimento científico, no cerne da atividade coletiva.
\end{abstract}

Palavras-chave: Conhecimento matemático; Coletividade; Formação inicial; Professores de matemática.

\begin{abstract}
This article aims to discuss the collectivity as a unit in the training of pre-service mathematics teacher, in a process of signifying knowledge, based on the assumptions of the Cultural-Historical Theory. Understanding what collective activity is related, both to the processes of construction of scientific knowledge systematized and organized by the school, and to the processes of appropriation of culture. With this, we present in this text reflections about the collectivity in the training of pre-service mathematics teachers and a synthesis about the research carried out, through training actions developed during an academic year with a group of students of the Mathematics Degree. Whose analysis led us to understand the movement of the history of mathematical knowledge, the search for the sharing of meanings, the conflicts that mobilize and transform the senses through the experiences lived with others and the humanization of scientific knowledge at the heart of collective activity.
\end{abstract}

Keywords: Mathematical knowledge; Collectivity; Pre-service teacher education; Math teachers.

\footnotetext{
* Mestre em Educação em Ciências e Matemática pela Universidade Federal de Goiás (UFG), Goiânia, Goiás, Brasil. Docente na Universidade Federal de Goiás (UFG), Goiânia, Goiás, Brasil. Rua da Divisa, Cond. Gran Royalle, apto 104, bl 10, Morada do Sol. CEP: 74473830. E-mail: maylineregina@ufg.br.

** Doutor em Educação pela Universidade de São Paulo (USP), São Paulo, São Paulo, Brasil. Docente na Universidade Federal de Goiás (UFG), Goiânia, Goiás, Brasil. E-mail: wcedro@ufg.br. 


\section{RESUMEN}

Este artículo tiene como objetivo discutir la colectividad como unidad en la formación inicial del profesor de matemáticas, en un proceso de conocimiento significante, a partir de los supuestos de la Teoría Histórico-Cultural. Comprender qué actividad colectiva se relaciona, tanto con los procesos de construcción del conocimiento científico sistematizado y organizado por la escuela, como con los procesos de apropiación de la cultura. Con ello, presentamos en este texto reflexiones sobre la colectividad en la formación inicial de profesores de matemáticas y una síntesis sobre la investigación realizada, a través de acciones formativas desarrolladas durante un curso académico con un grupo de alumnos de la Licenciatura en Matemáticas. Cuyo análisis nos llevó a comprender el movimiento de la historia del conocimiento matemático, la búsqueda del intercambio de significados, los conflictos que movilizan y transforman los sentidos a través de las vivencias vividas con el otro y la humanización del conocimiento científico en el seno de la actividad colectiva.

Palabras clave: Conocimiento matemático; Colectividad; Formación inicial; Profesores de matemáticas.

\section{INTRODUÇÃO}

Ao pensarmos sobre a formação inicial de professores de matemática, nos referimos também ao seu próprio conhecimento como uma ferramenta essencial e potencializadora da atividade humana pelo seu contexto histórico e social, bem como pela sua apropriação ao buscar maneiras de explicar, conhecer e interpretar o mundo. Longarezi e Franco afirma que:

o que permite o homem passar da consciência social para a individual é o processo de apropriação dos conhecimentos humanos produzidos anteriormente pelas gerações que o precederam, que ocorre mediante sua atividade em determinado contexto histórico e social (LONGAREZI; FRANCO, 2013, p. 83).

Nesse sentido, consideramos o professor o principal responsável pelo processo de ensino, no qual deve compreender essa atividade como uma forma da mediação do conhecimento, que reafirma a necessidade humana e a apropriação cultural no espaço escolar. Como afirmam Moretti e Moura (2010, p. 347), tal atividade "traduz-se como sendo a atividade humana intencional adequada a um fim e orientada por objetivos, por meio da qual o homem transforma a natureza e produz a si mesmo".

Analisando esse debate, temos a consciência relativa às dificuldades e paradigmas da formação inicial de professores de matemática, ao longo de nossa história, como sendo incipiente e com inúmeros fatores envolvidos no papel da educação escolar, tais como: a concepção de espaço escolar, o papel do professor e as necessidades do aluno, bem como o as relações coletivas em torno da significação do conhecimento estudo e sistematizado.

Dessa forma, qual o princípio entre a coletividade e a significação do conhecimento 
matemático? Primeiramente, entendemos que esse conhecimento faz parte do desenvolvimento da cultura humana, assim como afirma Caraça (1951, p. 13),

organismo vivo, impregnado de condição humana, com as suas forças e as suas fraquezas e subordinado às grandes necessidades do homem na sua luta pelo entendimento e pela libertação. [...] A Matemática possui problemas próprios que não têm ligação imediata com os outros problemas da vida social. Mas não há dúvida também de que seus fundamentos mergulham tanto como os de outro qualquer ramo da Ciência, na vida real; uns e outros entroncam na mesma madre (CARAÇA, 1951, p. 14).

Interpretando Caraça, podemos dizer que o desenvolvimento do conhecimento matemático permeia a necessidade de resolver um problema e a produção de significados na atividade humana. Assim, esse tipo de conhecimento possui um objetivo social que, segundo Moura (2007), é derivado de uma necessidade suscitada pelo coletivo, em que o indivíduo se apropria de novas sínteses que são geradas ao solucionar os problemas.

Com isso, afirmamos que a formação humana, por meio da apropriação de conhecimento científico, se constitui no interior da atividade coletiva, assim como aponta Leontiev (1983, p.114) “atrás das significações idiomáticas estão as formas de ação - operações - socialmente elaboradas, cujo processo das pessoas transformam e conhecem a realidade objetiva". Em outras palavras, a significação está contida de maneira "transformada e reduzida ao contexto idiomático, a forma ideal da existência do mundo objetal, de suas propriedades, nexos e relações, descobertos por meio da prática social conjunta" (LEONTIEV, 1983, p. 115). O autor, ainda, indica que os conceitos se constituem por meio da apropriação de significações historicamente elaboradas mediante à comunicação e às ações formativas, numa aquisição individual na consciência humana. É neste sentido que nos propomos a discutir, neste artigo, os aspectos da coletividade como unidade pedagógica na formação inicial do professor de matemática, em um processo de significação do conhecimento pelos pressupostos da Teoria Histórico-Cultural. Neste trabalho, abordamos o objeto de investigação "conhecimento do professor de matemática em formação inicial”, por meio de uma perspectiva pautada na Teoria Histórico-Cultural. As discussões apresentadas a seguir, propõem uma reflexão acerca do papel da coletividade na formação deste sujeito, cujo objetivo é discutir a coletividade como unidade na formação inicial do professor de matemática em um processo de significação do conhecimento.

O processo de significação do conhecimento matemático é entendido como a relação entre o sentido pessoal e o significado social de um determinado conceito. É nessa relação que 
compreendemos a apropriação do conhecimento matemático por um viés lógico-histórico, constituído pela coletividade.

Na formação inicial de professores de matemática, faz-se necessário a construção de uma relação coerente com aquilo que aprende, pois, segundo Leontiev (2004), os conhecimentos adquiridos convertem-se em conhecimentos vivos, que medeiam sua relação com a natureza. Nesse sentido, entendemos que a atividade do professor de matemática deve estar ligada diretamente com a formação de conceitos, o que nos leva a pensar sobre a constante transformação do professor, em sua atividade dotada de significações que lhes são próprias, mas que também emergem como produto histórico-cultural.

Acreditamos que na atividade de ensino, o professor potencializa: a organização do ensino em concordância com os pressupostos teóricos mencionados; a intencionalidade para possibilitar o desenvolvimento humano e a busca por novos conhecimentos. Dessa forma, nos propomos nessa reflexão acerca da perspectiva em que coletividade é considera uma unidade pedagógica, na formação inicial do professor de matemática e no processo de significação do conhecimento, podemos compreender a construção do conhecimento científico sistematizado e organizado pela escola, bem como os processos de apropriação da cultura. Assim, buscaremos responder à questão investigativa: Como, e por que a coletividade se torna elemento primordial na significação do conhecimento matemático para professores em formação inicial?

Com isso, apresentamos, neste artigo, alguns aspectos acerca: do tornar-se professor numa constituição humana, o papel da coletividade no desenvolvimento humano, a coletividade na formação inicial de professores de matemática, aspectos metodológicos, análise dos dados e uma síntese acerca da investigação realizada.

\section{O TORNAR-SE PROFESSOR POR MEIO DA CONSTITUIÇÃO HUMANA}

A apropriação das condições humanas necessita do desenvolvimento histórico da sociedade humana e de suas manifestações, como um conjunto de respostas para melhor satisfazer suas necessidades e, assim, apropriar-se do meio cultural. $\mathrm{O}$ homem pode apreender a cultura já constituída pelo seu povo até o momento de sua necessidade, como também pode criar elementos para renová-la, já que a cultura é um fator de humanização e o ser humano só se desenvolve enquanto homem porque vive em uma sociedade cercada de cultura.

A respeito da constituição do homem e de sua individualidade, entendemos o movimento de investigação tal qual Moretti e Cedro (2016, p. 75), colocam em que: “[...] a 
concepção de homem e de mundo na qual o homem por meio do trabalho, entendido como atividade intencional, transforma a realidade e produz-se a si mesmo. Assim, é a atividade material do homem que se constitui na mediação entre ele e o mundo".

Sendo o homem um produto cultural determinado pelo seu trabalho, que modifica a realidade por meio de suas ações, em que está presente o valor da prática social e das ações coletivas, manifesta suas contradições como forma de síntese da realidade apreendida. Pela coletividade compreendemos os sujeitos em suas relações com o conhecimento científico e sua constituição enquanto homem social-crítico: “Assim, a ação humana é educativa e permanente, que se faz aprendendo e se aprende fazendo, ou, simplesmente, se faz e se pensa por meio da autoeducação e suas transformações na natureza, criando um mundo movido pelas suas necessidades" (SILVA, 2019, p. 13).

Como afirmam Moura, Sforni e Araújo (2011, p.40), “tornar possível que esses bens culturais sejam apropriados por todos os sujeitos é a finalidade educativa. Tal finalidade colocanos diante do desafio de encontrar meios de ensino que promovam essa apropriação". Ainda, segundo Paro (2010, p.25), o homem,

[...] se torna mais humano (histórico) à medida que desenvolve suas potencialidades, que à sua natureza vai acrescentando cultura, pela apropriação de conhecimentos, valores, crenças, habilidades artísticas etc. É pela apropriação dos elementos culturais, que passam a constituir sua personalidade viva, que o homem se faz humanohistórico. (Paro, 2010, p.25).

Em nossa perspectiva, em relação à constituição do homem e da apropriação cultural, entendemos que ser professor transcende o ato de ensinar conteúdos, sendo um processo contínuo e prescrevendo uma relação intrínseca com a prática no exercício de sua profissão. Nessa perspectiva, a formação do professor não ocorre de forma individual, pois sua constituição enquanto professor baseia-se nas experiências vividas e no compartilhamento de suas ações e perspectivas ao ressignificar os sentidos acerca dos significados de ser e se tornar professor.

Neste sentido, conforme aponta Lopes (2009, p.55), o homem não nasce professor: “[...] ele se constitui historicamente; aprende sem se desvincular do mundo que o rodeia; aprende com o outro e aprende também refletindo. O saber e o fazer constituem-se em elos inseparáveis. Formar-se professor é mais do que somente frequentar um curso superior” (LOPES, 2019, p. $55)$. 
A proposta se deu, conforme estudos levantados em Silva (2019), por Crescenti (2005), Corbo (2012), Damico (2007), Figueiredo (2007), Moreira (2004) e Prado (2008), indicando que na formação inicial de professores de matemática, o conhecimento emerge carregado de sentidos construídos historicamente. Em nosso caso, o conhecimento matemático, que corroborando com Serrazina (2002, p. 11) “além dos conteúdos matemáticos, é importante, num curso de formação inicial, propiciar que os alunos, futuros professores, desenvolvam uma atitude de investigação e de constante questionamento em Matemática", com objetivo de constituir novos motivos para este conhecimento. Compreendendo, assim, o papel do professor de matemática em promover a mediação, para que seus alunos se apropriem de conceitos produzidos historicamente. Ele, então, se torna um criador de sentidos que, em movimento, se modificam, gerando suas próprias significações em um processo de questionamento do próprio conhecimento matemático.

Nessa perspectiva de conhecimento, entendemos que este constitui-se como produto histórico-cultural, que se fundamenta por meio da linguagem e tem importante relevância na interação com o meio e na elaboração de conceitos que relacionam entre si, para que ocorra a aprendizagem pela produção de sentidos, na atividade coletiva.

A atividade coletiva, assim como aponta Leontiev, propõe-se uma formação humana por meio da apropriação de conhecimento científico, em que:

\begin{abstract}
As significações refletem o mundo na consciência do homem. Atrás das significações idiomáticas estão as formas de ação - operações - socialmente elaboradas, cujo processo das pessoas transformam e conhecem a realidade objetiva. Em outras palavras, a significação está contida de maneira transformada e reduzida ao contexto idiomático, a forma ideal da existência do mundo objetal, de suas propriedades, nexos e relações, descobertos por meio da prática social conjunta (LEONTIEV, 1983, p. 115).
\end{abstract}

Neste intuito, compreendemos e defendemos que a atividade coletiva está relacionada tantos aos processos de construção do conhecimento científico sistematizado e organizado pela escola, quanto nos processos de apropriação da cultura, aos quais chamamos de conhecimento matemático. Em outras palavras, a atividade coletiva deve ser elemento essencial para compreender as necessidades do conhecimento matemático, bem como organizar o ensino deste e suas necessidades sociais de hoje. 


\section{O PAPEL DA COLETIVIDADE NO DESENVOLVIMENTO HUMANO}

O gênero humano se constitui, segundo Leontiev (1978), por meio das relações com as múltiplas determinações de si próprio e da cultura humana que é coletiva. Essas relações com o real nos interconectam por meio de: contradições, movimento e transformações do objeto em estudo. Assim, podemos dizer que o homem diante do mundo não é completamente passivo e natural, ele transforma o meio em que vive a partir de suas necessidades. E é isso que o humaniza.

Segundo Lanner de Moura e outros (2016, p. 363), "O homem tem a sua individualidade, mas ela só se constitui em atividade coletiva, em sociedade e pela linguagem, como produto de suas significações”. Assim, com o uso da linguagem, o homem relaciona-se dialeticamente com a natureza, se transforma para elaborar produtos que satisfarão suas necessidades. Essa relação é caracterizada como trabalho, que é uma condição de existência do homem em sua relação com a natureza e, portanto, da vida humana.

Conforme as ideias de Leontiev (1978), quando nasce, o ser biológico não tem subsídios suficientes para viver em sociedade com os outros. Para o auto, (1978, p. 267), “o indivíduo é colocado diante de uma imensidade de riquezas acumuladas ao longo dos séculos por inumeráveis gerações de homens, os únicos seres, no nosso planeta, que são criadores". O homem se apropria da cultura existente e também pode criar elementos para ressignificá-la ou elaborar um novo conhecimento. Assim, podemos entender que a cultura é um elemento humanizador e o ser humano se desenvolve vivendo em uma sociedade, emergido em sua cultura.

\footnotetext{
Os homens criam os objetos que devem satisfazer as suas necessidades e igualmente os meios de produção destes objetos, dos instrumentos às máquinas mais complexas. Constroem habitações, produzem as suas roupas e outros bens materiais. Os progressos realizados na produção de bens materiais são acompanhados pelo desenvolvimento da cultura dos homens; o seu conhecimento do mundo circundante e deles mesmos enriquece-se, desenvolvem-se a ciência e a arte (LEONTIEV, 1978, p. 265).
}

Desse modo, entendemos a educação escolar como unidade intrinsecamente relacionada ao trabalho que influencia a formação humana, já que o trabalho é a relação dialética entre o homem e a natureza, com objetivo de criar objetos ou produtos que satisfaçam as necessidades humanas. "Com as contradições das múltiplas determinações, nos tornamos humano, uma vez que produzimos sínteses de nós mesmos para como a natureza. Isso ocorre por meio da 
apropriação cultural humana e de nossa emancipação guiada pelo conhecimento científico", pela análise de Silva (2019, p. 13).

Leontiev, ainda, afirma que os conceitos se constituem por meio do resultado do processo de apropriação de significações historicamente elaboradas, o que ocorre na atividade humana, em condições de comunicação com o grupo. Com a comunicação, as ações formativas da investigação podem ser pensadas como uma apropriação individual na consciência humana. Dessa forma, discutiremos o papel da coletividade no processo de significação do conhecimento matemático, buscando uma organização educacional que propicie aos sujeitos elevar a qualidade do conhecimento produzidos pela humanidade por meio de experiências.

\section{A COLETIVIDADE NA FORMAÇÃO INICIAL DE PROFESSORES DE MATEMÁTICA}

Entendemos que a escola é um espaço estrategicamente organizado e destinado ao processo de ensino e aprendizagem. Nesse espaço, o professor de matemática tem como atividade principal o ato de ensinar conceitos matemáticos, enquanto indivíduo crítico, histórico e intencional. Conectado a isso, a respeito da formação inicial de professores de matemática, que os prepara para adentrar nesse espaço escolar, podemos perceber que o conhecimento humaniza, pelo contexto histórico e social, quando busca maneiras de explicar, conhecer e interpretar o mundo.

De acordo com Longarezi e Franco (2013, p.83): “o que permite o homem passar da consciência social para a individual é o processo de apropriação dos conhecimentos humanos produzidos anteriormente pelas gerações que o precederam, que ocorre mediante sua atividade em determinado contexto histórico e social".

Dessa forma, o professor compreende seu trabalho como mediação das ações que geram conhecimento, evidenciando as necessidades humanas e culturais. Assim como uma atividade intencional e consciente, que compõem sua atividade pedagógica para possibilitar o desenvolvimento humano.

Concordando com Moretti e Moura (2010, p. 347), tal atividade "traduz-se como sendo a atividade humana intencional adequada a um fim e orientada por objetivos, por meio da qual o homem transforma a natureza e produz a si mesmo". Assim, podemos conjecturar que a Matemática tem um objetivo social que, segundo Moura (2007), é derivado de uma necessidade suscitada pelo coletivo, em que o indivíduo se apropria de novas sínteses que são geradas ao 
solucionar os problemas. Assim, as necessidades geram ações e operações que, ao serem construídas com instrumentos, potencializam a vida humana por meio do conhecimento.

De acordo com Leontiev (1983), o ser humano vê-se imerso em um mundo de significações a partir das atividades que desenvolve, assim, o conhecimento emerge carregado de sentidos construídos historicamente, como essas significações que se manifestam pelo conhecimento e pela cultura, se tornam, para o ser humano, sentidos conforme o objeto estudado. Em outro texto, Leontiev (2004) diz que os conhecimentos adquiridos convertem-se em conhecimentos vivos, que medeiam sua relação com o mundo, o que também podemos pensar para a formação inicial de professores de matemática. Dessa forma, o que motiva os sujeitos, é promovido por meio dos sentidos que atribuem ao conhecimento, os motivos que os incitam a pensar e a agir. Ainda segundo o autor, o motivo mobiliza as ações que possibilitam o desenvolvimento de uma determinada tarefa, sendo o motivo uma relação adquirida por meio dos sentidos. Com isso, podemos conjecturar que ensinar matemática transcende a tarefa determinada pelo conteúdo, pois ela deve emergir do sentido que o estudante atribui à atividade que realiza.

Ao pensarmos nessa transformação dos motivos Leontiev (2004), nos afirma que existem dois tipos deles: o motivo eficaz ou motivo gerador de sentido e o motivo compreendido ou motivo-estímulo. Ainda de acordo com Leontiev (1983, p.239), “[...] a diferença aqui estará não somente no aproveitamento que o sujeito tem da atividade desenvolvida, mas também no grau de sua conscientização, no lugar que a atividade ocupa na formação de sua personalidade e em que sentido adquire para ele".

Portanto, para a formação inicial de professores de matemática, compreendemos que, para que a atividade docente cumpra seu papel social, é necessário que tenhamos motivos geradores de sentidos, de acordo com a perspectiva de Leontiev. Nesse sentido, concordamos com Serrazina (2002, p. 11), ao dizer que “[...] além dos conteúdos matemáticos, é importante, num curso de formação inicial, propiciar que os alunos, futuros professores, desenvolvam [...] uma atitude de investigação e de constante questionamento em Matemática." Além disso, é necessário gerar motivos novos para avançar na qualidade do conhecimento matemático, também para esse sujeito, prestes a adentrar no espaço escolar.

Então, interconectando a discussão teórico-metodológica feita até aqui, podemos dizer que, a produção de sentido se dá por meio da atividade coletiva, o que categoriza as ações individuais para transformá-las em ações humanas. Assim, pelo desenvolvimento da coletividade, o homem pode produzir sentido e relacionar os motivos da atividade aos objetos 
das ações realizadas e aos objetivos que se pretende estudar. Corroborando a isso, Cedro (2008, p. 16) indica que na formação de professores há "lugar para produção e troca de significados constitutivos para o sentido das ações de todos os indivíduos envolvidos na atividade educativa, entendendo-a como um espaço de aprendizagem".

Assim, a atividade do professor está relacionada à formação de conceitos, isto é, "este é um profissional que poderíamos chamar de criador de sentido para o que é ensinado e sua ferramenta principal é a palavra”, de acordo com Moura (2004, p. 258). O que nos promove uma reflexão acerca da transformação do professor, conforme as significações de sua atividade, que também emergem como produto histórico-cultural da sociedade, pois o processo de significação do conhecimento matemático pode ser potencializado conforme as situações coletivas e o compartilhamento de significados, neste caso a respeito da organização do ensino de matemática, em prol da humanização dos sujeitos envolvidos.

Com esse pensamento, trazemos, no item a seguir, uma síntese a respeito da análise de uma experiência vivenciada pelos autores deste texto, em que tratarmos do papel da coletividade nos processos de formação inicial de professores de matemática, e que viabilizou as discussões acerca da significação do conhecimento matemático e suas relações com a coletividade.

\section{ASPECTOS METODOLÓGICOS DA INVESTIGAÇÃO}

Em meio às vivências na pesquisa, destacamos alguns momentos que compartilhamos a seguir. O grupo que compôs os sujeitos desse estudo, eram estudantes de Licenciatura em Matemática e que estavam em diferentes períodos da formação, porém, participavam de um projeto da universidade vinculado à pesquisa, planejamentos e desenvolvimento de tarefas de ensino em escolas públicas, tarefas essas relacionadas à perspectiva teórico-metodológica que corrobora com a discussão deste artigo.

A investigação foi desenvolvida em uma universidade federal brasileira, as ações envolvidas na pesquisa foram registradas em um grupo de estudos do qual participavam quatro estudantes, a pesquisadora e o professor orientador da investigação. O principal objetivo do grupo de estudos era promover discussões acerca do movimento lógico-histórico do conhecimento matemático e o compartilhamento das ações de planejamento e organização do ensino de matemática. 
A pesquisa mencionada na introdução deste artigo refere-se a um estudo realizado no ano letivo de 2017, por meio de uma pesquisa de dissertação de mestrado, seguindo a perspectiva teórica discutida no item anterior.

Os encontros aconteceram durante todo o ano letivo de 2017, sendo um encontro semanal com duração média de três horas. Tivemos, ao todo, vinte encontros formativos com o grupo de estudos. O objetivo principal da investigação com estes encontros do grupo de estudos, era apreender o fenômeno buscando indícios para compreender o processo de significação do conhecimento matemático em professores de matemática em formação inicial.

Para tanto, como instrumentos de organização de dados optamos por realizar uma entrevista inicial e outra no final do processo formativo; além dos relatos de experiência dos estudantes nas intervenções nas escolas, gravações audiovisuais de todos os encontros e suas respectivas transcrições, diário de bordo e narrativas elaboradas pelos sujeitos investigados.

Tais instrumentos proporcionaram uma análise, configurando o objeto de estudo. De maneira geral, podemos caracterizar os encontros formativos do grupo de estudos como transformadores da qualidade, em relação aos dos dados construídos, e em consonância aos processos de apropriação de conhecimentos matemáticos pelos indivíduos.

Essa proposta metodológica foi elaborada corroborando com ideias como afirmaram Dias e Moretti (2011), sobre a formação de professores de matemática, que uma proposta de trabalho deve colocar os futuros professores em atividade de ensino - lembrando que, conforme Leontiev (1978), o sentido que o indivíduo dá para sua atividade constitui sua própria atividade. Desta forma, conforme Dias e Moretti (2007, p.104), “estando o professor em atividade de ensino, as ações que ele propõe visam responder a sua necessidade de organização intencional do ensino". Essa compreensão leva o professor a planejar suas ações prevendo a necessidade de momentos de produção em grupos e de socializações de tais produções, "criando condições para que se estabeleça mediações necessárias entre alunos e o conhecimento de forma que se dê a aprendizagem por meio das apropriações que os sujeitos estabelecem sobre conhecimentos que são construções sócio-históricas”, corroborando ainda com as autoras Dias e Moretti (2007, p. 104).

As contribuições dos estudos que tivemos no decorrer do ano de 2017 com este grupo de estudantes da Licenciatura em Matemática, permitiram que chegássemos à conclusão de que organizar espaços formativos de maneira intencional a potencializar a formação docente de futuros professores faz uma enorme diferença na constituição da identidade profissional. 
Acreditamos que este movimento pensado para atividade de ensino oportuniza um processo de compartilhamento de significados, além de propiciar ao professor condições de criação de ferramentas e elaboração de planejamento que favoreçam a aprendizagem numa perspectiva humanizadora.

Com intuito de mostrar aos leitores uma possibilidade para a constituição de um espaço formativo que corrobora com a discussão até aqui apresentada, acerca da significação do conhecimento matemático por meio do estudo do movimento lógico-histórico deste, fizemos um breve recorte da análise da experiência vivenciada na investigação.

\section{O PAPEL DA COLETIVIDADE NOS PROCESSOS FORMATIVOS DA INVESTIGAÇÃO}

Em um dado momento de nossas reuniões, tivemos a necessidade de criar uma tarefa de ensino sobre o conceito de ângulo. No entanto, não tivemos êxito. Chamamos de "O problema conceitual do ângulo", que surgiu a partir dessa discussão do grupo ${ }^{1}$, enquanto tentávamos elaborar uma tarefa de ensino a respeito do conceito de ângulo. Destacamos, a seguir, uma fala do momento em questão.

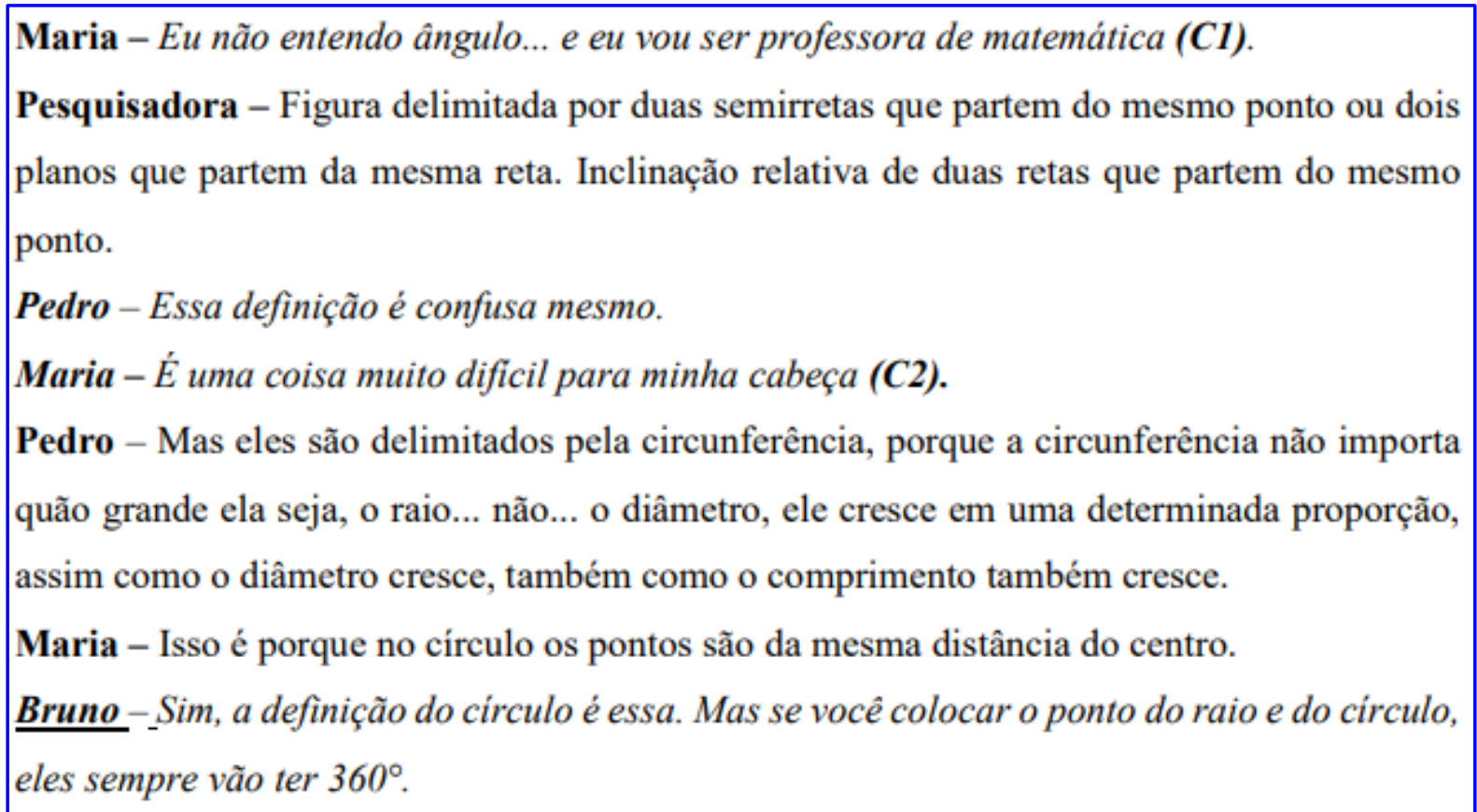

Figura 1. Diálogo - o problema conceitual do ângulo Fonte: SILVA (2019, p. 124).

${ }^{1}$ Todos os nomes citados como sujeitos(as) da investigação apresentam-se enquanto nomes fictícios. 
Nesta investigação, consideramos essencial para o processo de significação do conhecimento matemático o compartilhamento das ações entre os sujeitos de forma ativa, para compreendermos o papel do grupo nesse movimento de constituição do conhecimento matemático.

No trecho destacado, podemos observar o momento em que os sujeitos se deparam com questões acerca do conceito de ângulo e colocam em conflitos suas concepções sobre este, precisamente na fala de Maria. "Nossa interpretação, foi no sentido da confiança em relação ao grupo diante de sua manifestação e a necessidade de ser apropriado o pensamento teórico deste conceito de forma coletiva com as contribuições do grupo". O que corroboramos com Pereira (2011, p.37), ao afirmar que a formação tem de ser entendida como "um processo de troca e de criação coletiva, em que a intervenção daquele que conduz faz-se com certos conhecimentos e competências, estando ele igualmente a aprender com os outros".

Nesse sentido, notamos os conflitos a respeito da significação do conceito de ângulo, em que temos a ideia empírica de uma definição, porém, não podemos compreender seu significado, o que torna a atividade docente alienada. Isto significa dizer que, de acordo com Cedro e Moura (2011), a alienação é decorrente da formação inicial de professores, na qual não há a possibilidade de entender o que é a atividade pedagógica mediante à responsabilidade social do conhecimento matemático.

Segundo Pérez Gomes (2001, p. 169), a atividade individual do professor é um fator propício para o cultivo do pragmatismo, da passividade, da reprodução conservadora ou da fácil aceitação da cultura social dominante; ou seja, da alienação. Assim, esse isolamento somente “conduz à afirmação das diferenças, à estimulação da criatividade, à busca de alternativas originais e está impedindo, pelo contrário, a colaboração e o enriquecimento mútuo dos docentes".

No movimento de significação do conhecimento, os professores se colocam em atividade de estudo para a promoção coletiva da organização do ensino, assim, conforme aponta Moura (2011, p. 94), “os sujeitos, ao participarem de modo colaborativo da criação de atividades orientadoras de ensino, o fazem mediados por conceitos que proporcionarão a construção de significados pelo coletivo".

Cada indivíduo, apropria-se do que foi produzido coletivamente, possibilitando a criação de sentidos que modificam "concepções, responsáveis por novas ações, criadas para impactar as realidades simbólicas dos educandos com os quais atua”, assim afirma Moura 
(2011, p. 95). As diversas experiências coletivas e individuais contribuem no entendimento do grupo, como indica Polivanova (1996, p. 151), ao esclarecer que o compartilhamento de ações se manifesta quando os sujeitos se encontram em uma atividade cognitiva produtiva, "através de um nível elevado de estruturação da atividade intelectual, e num efeito intensificado da reflexão, do planejamento, do controle e da avaliação".

Para Moura (2000), é na coletividade que o trabalho do professor, que possui objetivos sociais, coloca-se de forma integral com vistas ao avanço do grupo. Aqui a troca de experiências também contribui para a atividade docente, principalmente ao aprenderem novas maneiras de desenvolver o trabalho e compartilhar suas experiências, como acorreu com o conceito de ângulo. Além disso, Rubtsov (1996), ao definir uma atividade em comum com o grupo, sendo elas: a compreensão mútua, a comunicação e o planejamento das ações individuais, levando em conta as ações dos parceiros com vistas a obter um resultado comum.

Contudo, acreditamos que não é possível pensar na atividade pedagógica sem pensar no coletivo, nas trocas de experiências e na significação do conhecimento. Assim, juntamente com Lopes (2011, p. 65), entendemos que a educação e o professor são o resultado da coletividade do espaço formativo e que esse profissional "só vai existir como educador quando conseguir compartilhar não só as responsabilidades de educar, mas também o próprio conhecimento".

Um dos instrumentos que fez parte da construção dos dados da pesquisa diz respeito as narrativas, que durante o desenvolvimento do grupo de estudos foram designadas em algum momento específico ${ }^{2}$ com objetivo de reflexão sobre a participação dos sujeitos, no projeto vinculado à pesquisa, tanto no ambiente escolar como nas reuniões de planejamento e avaliação e nas ações formativas destinadas a esta investigação.

Em diversos momentos, identificamos indícios a respeito da influência do trabalho coletivo com o qual nos propusemos. Dentre estes momentos, destacamos um trecho escrito por Pedro, que nos chamou bastante atenção. Vejamos a seguir. 
\begin{tabular}{l} 
Pedro: Para além dos resultados e conclusões teóricas, estamos vivendo em meio a esse \\
movimento, nós, as crianças, e nesse viver nos encontrando motivados, valorizados e felizes \\
pelo que fazemos, por contribuir e receber contribuições, isso está além de muitos outros \\
objetivos "profissionais" colocados aqui, mas que se encontram interligados, ao processo \\
de humanização, de motivação dos seres, de valorização do ser humano e do ser fazer \\
constante (E1). Por isso acredito que a contribuição que o clube nos dá vai muito além da \\
prática docente, o clube nos dá claras contribuições para a vida, para o cotidiano, nas mais \\
diversas situações do viver. A coletividade, o trabalho em equipe, o respeito ao próximo e a \\
si mesmo, o auto reconhecimento, a valorização e autoestima conquistada nas atividades, a \\
capacidade de criação e de resolução de situaçães problemas são aspectos que movem a \\
“espiritualidade" do homem e que estão além da ciência e dos conhecimentos matemáticos \\
\hline
\end{tabular}

Figura 2. Trecho escrito por Pedro, em uma de suas narrativas Fonte: SILVA (2019, p. 129).

No trecho da narrativa, podemos identificar indícios de que a coletividade transforma significados pelo processo de humanização mediante a atividade docente e a emancipação por meio do conhecimento científico. E ao estabelecermos interações com o que é universal, o homem transforma o ambiente e a si mesmo, enquanto, por meio do trabalho, valoriza a prática social e as ações coletivas.

Vimos que a coletividade e as transformações das múltiplas determinações que compreendem as relações dos sujeitos, em que a significação do conhecimento matemático se torna um elemento primordial para a constituição do humano. Em consonância a estas ideias, para Paro (2010, p.25), o homem [...] "se torna mais humano (histórico) à medida que desenvolve suas potencialidades, que à sua natureza vai acrescentando cultura, pela apropriação de conhecimentos, valores, crenças, habilidades artísticas etc.”. Ainda, segundo o autor, é pela apropriação dos elementos culturais que "passam a constituir sua personalidade viva, que o homem se faz humano-histórico".

Nesse momento, há indícios de que tornar-se professor de matemática também é uma forma de emancipação por meio da coletividade.

Compreender os processos históricos do desenvolvimento do conhecimento diante da humanidade faz parte de uma das competências do professor, que se apropria desse fazer com o outro, pelas relações e vivências com o grupo, pela troca de significados e embates de contradições de ideologias (SILVA, 2019, p. 133). 
Na narrativa de Pedro, podemos perceber a formação do pensamento mediante os aspectos da coletividade como base do espaço de aprendizagem investigado. Assim, entendemos que o caminho para a humanização, por meio da apropriação do conhecimento matemático, é social, como aponta Leontiev (1978), e tudo o que provém das relações com o outro e com o meio são frutos das vivências em sociedade.

Temos dito que as esferas envolvidas na formação inicial do professor de matemática estão fragmentadas, ocasionando diversas rupturas nos processos formativos. Dentre essas rupturas, destacamos um trecho a respeito das limitações em relação ao conhecimento matemático que os próprios sujeitos identificaram diante das ações formativas propostas ao analisarem uma tarefa desenvolvida no ambiente escolar, em que os mesmos concluíram de forma negativa o desfecho dos objetivos das ações a respeito do conteúdo matemático pretendido.

Com isso, pudemos notar, em conjunto, a necessidade de estudo a respeito da síntese histórico-lógica dos conceitos matemáticos, que de acordo com os próprios estudantes, foi o principal limitador da tarefa em questão. Podemos perceber no diálogo abaixo a necessidade de estudo em relação ao conhecimento matemática.

Orientador: Mas o que a gente tem é a limitação que a está dizendo. Nós não temos uma formação mais ampla possivel, para a gente poder olhar essas coisas, para a gente poder ter essa possibilidade. Então, quando a agente tem a formação, boa parte, que a gente teve era para estudar uma coisa.

Vitória: É... a gente ainda encontra problemas nas nossas próprias atividades.

Pedro: É, mas não tem problema você achar problema nas coisas...

Vitória: Não, não tem problema achar problema, mas isso é sinal de que em algum momento ali a gente não conseguiu dar conta.... então, a gente vai, volta, reflete, tenta fazer de novo ou então descarta, mas a gente encontra problema em uma coisa que a gente está sempre estudando.

Figura 3. Reflexões sobre as tarefas do projeto e a necessidade de estudo Fonte: SILVA (2019, p. 132). 
Segundo Cedro (2008), compartilhar os saberes individuais permite aos sujeitos que estão envolvidos no processo atingirem um nível adequado de pensamento, o que envolve aspectos de cooperação.

Com o trecho apresentado acima, podemos notar indícios de conscientização acerca dos processos de significação do conhecimento matemático em relação a produção coletiva do conhecimento. A proposta coletiva de socialização de tais conhecimentos permite também a ação coletiva de planejar, selecionar os instrumentos, distribuir funções, assim em como avaliar a relação do sujeito com o ambiente social, cujo objetivo é gerar novos sentidos para a atividade docente. Assim, tais experiências que enfatizem o compartilhamento podem potencializar a produção de novos sentidos e promover nova compreensão da atividade docente, o que nos mostra o modo de organização das ações formativas em que possibilitamos a inserção dos futuros professores na construção de uma identidade docente, com a promoção do processo de significação do conhecimento matemático.

Nesse sentido, Rubtsov (1996, p.136) afirma que uma atividade pode ser caracterizada como atividade coletiva se contiver alguns dos seguintes elementos essenciais:

\begin{abstract}
A repartição das ações e das operações iniciais, segundo as condições da transformação comum do modelo construído no momento da atividade; A troca de modos de ação, determinada pela necessidade de introduzir diferentes modelos de ação, como meio de transformação comum do modelo; A compreensão mútua, permitindo obter uma relação entre, de um lado, a própria ação e seu resultado e, de outro, as ações de um dos participantes em relação a outro; A comunicação, assegurando a repartição, a troca e a compreensão mútua; $O$ planejamento das ações individuais, levando em conta as ações dos parceiros com vistas a obter um resultado comum; A reflexão, permitindo ultrapassar os limites das ações individuais em relação ao esquema geral da atividade (RUBTSOV, 1996, p.136).
\end{abstract}

Os elementos apontados por Rubtsov (1996) acerca da atividade coletiva, nos permitem estabelecer relações entre a atividade de aprendizagem e a atividade de ensino, ao fornecer indicadores sobre a organização do trabalho pedagógico, dos quais destacamos a comunicação e a compreensão mútua da problemática comum em prol do processo de significação do conhecimento matemático, o que também corrobora o trabalho de Nóvoa (2011). Segundo ele, o que dá sentido à formação é o diálogo entre os professores, a análise rigorosa das práticas e a procura coletiva das melhores formas de agir.

O compartilhamento das ações, segundo Polivanova (1996, p.151), "se manifesta em uma atividade cognitiva produtiva através de um nível elevado de estruturação da atividade intelectual, e num intensificado da reflexão, do controle e da avaliação". A apropriação da 
cultura é interiorizada pelos indivíduos, em que, segundo Davidov (1988), a interiorização constitui-se na transformação da atividade coletiva em uma atividade.

\begin{abstract}
Essa transformação é possível, então, por meio da comunicação entre as pessoas. Isto nos possibilitou entender como ações do professor, ao estudar os conceitos a serem apropriados pelos estudantes; além de organizá-los e recriá-los para que possam ser apropriados, de modo que as ações individuais sejam providas de significado social e sentido pessoal na divisão de trabalho do coletivo; e refletir sobre a eficiência das ações se realmente conduziu aos resultados inicialmente idealizados (SILVA, 2019, p. 131).
\end{abstract}

Para Davidov (1998, p.131), "a transição ao processo de trabalho significa simultaneamente a transição do homem à atividade conjunta, à atividade coletiva", o que está vinculado ao compartilhamento das ações e da compreensão dos objetivos. Assim, a característica essencial da atividade docente pode ser superada no sentido da alienação, pela da divisão do trabalho. A concretização de um ambiente coletivo, que atua sobre o modo como o compartilhamento permite a transformação de uma situação em um modelo geral de ação (RUBTSOV, 1996), onde o objeto de sua ação se manifesta como um modo para a organização do ensino, em que se incorporam novos elementos por meio de ações compartilhadas.

Com isso, percebemos o quão a coletividade, no processo de significação do conhecimento matemático, impacta a formação humana por meio das ações e operações elaboradas socialmente. Além disso, o processo formativo corrobora com a universalidade cultural, produzidos pela humanidade, na condição das aquisições individuais que está intrinsecamente conectada à forma e o conteúdo privilegiado nas práticas sociais.

\title{
7 ALGUMAS CONSIDERAÇÕES
}

Acreditamos que o caminho para a humanização, por meio da apropriação cultural em relação ao conhecimento matemático, é social, como aponta Leontiev (1978), e tudo o que provém das relações com o outro e com o meio são frutos das vivências em sociedade. Promover a significação desse conhecimento científico, juntamente com os professores em formação, segundo Silva (2019, p.134) "é ter a intenção de que o professor, em sua coletividade, possa ser agente promotor na conquista da emancipação humana, organizando com qualidade o ensino adequado, com objetivo de educar integralmente seus alunos". Ou, como mostra Vigotski (1991), é educar o cidadão a partir da assimilação ativa dos conteúdos. 
O papel da coletividade no processo de significação do conhecimento matemático, nos dá indícios de impactos na formação humana. Pois, acreditamos que tratar do processo de significação do conhecimento matemático é lidar com ações e operações elaboradas socialmente. Além disso, o processo formativo corrobora com a universalidade cultural, produzidos pela humanidade, na condição das aquisições individuais que está intrinsecamente conectada à forma e o conteúdo privilegiado nas práticas sociais.

Nesse sentido, consideramos que o envolvimento coletivo no processo de significação está expresso na:

\begin{abstract}
a) compreensão do movimento da história do conhecimento matemático como síntese da humanidade como um todo, e não como elaboração individual de gênios; b) busca pelo compartilhamento de significados; c) conflitos que mobilizam e transformam os sentidos por meio das experiências vivenciadas com o outro; d) humanização do conhecimento científico no cerne da atividade coletiva (SILVA, 2019, p. 154).
\end{abstract}

Com isso, acreditamos que é por meio da coletividade que o homem produz sentido, que por sua vez, relaciona-se aos motivos da atividade e aos objetos das ações realizadas. Além disso, a atividade do professor está ligada diretamente à formação de conceitos, o que nos leva a refletir sobre a constante transformação do professor em sua atividade, dotada de significações que lhes são próprias, mas que também emergem como produto coletivo histórico-cultural da sociedade.

\title{
REFERÊNCIAS
}

CARAÇA, B. Conceitos fundamentais da Matemática. Lisboa: Gradiva, 1951.

CEDRO W. L. O motivo e a atividade de aprendizagem do professor de matemática: uma perspectiva histórico-cultural. Tese (doutorado) - Programa de Pós-graduação em Educação, Universidade de São Paulo, São Paulo, 2008. Disponível em: https://teses.usp.br/teses/disponiveis/48/48134/tde-17122009-080649/pt-br.php. Acesso em: 31 mai. 2021.

CEDRO, W. L; MOURA, M. O. O Clube de Matemática: um espaço para a formação inicial de professores que ensinam matemática. Perspectivas da Educação Matemática - Revista do Programa de Pós-Graduação em Educação Matemática da UFMS, 2011. Disponível em: https://periodicos.ufms.br/index.php/pedmat/article/view/2769. Acesso em: 31 mai. 2021.

CORBO, O. Um estudo sobre os conhecimentos necessários ao professor de Matemática para a exploração de noções concernentes aos números irracionais na Educação Básica. Tese (doutorado) - Uniban, São Paulo, 2012. 
CRESCENTI, E. P. Os professores de Matemática e a Geometria: opiniões sobre a área e seu ensino. Tese (doutorado) - UFSCar, São Carlos, 2005. Disponível em:

https://repositorio.ufscar.br/handle/ufscar/2380?show=full. Acesso em: 31 mai. 2021.

DAMICO, A. Uma investigação sobre a formação inicial de professores de Matemática para o ensino de números racionais no Ensino Fundamental. Tese (doutorado) - Uniban, São Paulo, 2007. Disponível em: https://tede2.pucsp.br/handle/handle/11245. Acesso em: 31 mai. 2021.

DAVÍDOV, V. V. La enseñanza escolar y el desarrollo psíquico: investigación teórica y experimental. Moscú: Progreso, 1988.

DIAS, M. S; MORETTI, V. D. Números e Operações: elementos lógico-históricos para atividade de ensino. Curitiba: IBPEX, 2011. 188p.

FIGUEIREDO, A. C. Saberes e concepções de educação algébrica em um curso de Licenciatura em Matemática. Tese (doutorado) - PUC/SP, São Paulo, 2007. Disponível em: https://tede2.pucsp.br/handle/handle/11255. Acesso em: 31 mai. 2021

LANNER DE MOURA, A. R. et al. Educar com a Matemática - Fundamentos. São Paulo: Cortez, 2016.

LEONTIEV, A. N. O desenvolvimento do psiquismo. São Paulo: Centauro, 2004.

LEONTIEV, A. N. Selected psychological works. Soviet Education, Moscow, USSR, v. 43, n. 1, p. 52-87, 1983.

LEONTIEV, A. N. Actividad, conciencia y personalidad. Buenos Aires: Ediciones Ciencias del Hombre, 1978.

LONGAREZI, A. M.; FRANCO, P. L. J. Educação escolar enquanto unidade significado social/sentido pessoal. Nuances: estudos sobre educação, Presidente Prudente, v. 24, n. 1, p. 92-109, 2013. http://dx.doi.org/10.14572/nuances.v24i1.2157.

LOPES, A. R. L. V. Clube de Matemática: a formação inicial de professores e o estágio compartilhado. In: Anais do VIII ENEM-Encontro Nacional de Educação matemática, Recife, 2011. p. 01-17.

LOPES, A. R. L. V. Aprendizagem da docência em matemática: o Clube de Matemática como espaço de formação inicial de professores. Passo Fundo: Ed. Universidade de Passo Fundo, 2009.

MOREIRA, P. C. O conhecimento matemático do professor: formação na Licenciatura e prática docente na escola básica. Tese (doutorado) - UFMG, Belo Horizonte, 2004.

Disponível em: https://repositorio.ufmg.br/handle/1843/EABA-6ABMUH. Acesso em: 31 mai. 2021.

MORETTI, V. D.; MOURA, M. O. A Formação Docente na Perspectiva Histórico-Cultural: em busca da superação da competência individual. Psicologia política, v. 10. n. 20. p. 345- 
361, jul-dez., 2010. Disponível em:

http://pepsic.bvsalud.org/scielo.php?script=sci_arttext\&pid=S1519-549X2010000200012.

Acesso em 31 mai. 2021.

MORETTI, V. D; CEDRO, W. L. Editorial: Mathematics Education and Cultural-Historical Theory. Revista Internacional de Pesquisa em Educação Matemática (RIPEM), v. 6, p. 24, 2016. Disponível em:

http://sbem.iuri0094.hospedagemdesites.ws/revista/index.php/ripem/article/view/1208.

Acesso em: 31 mai. 2021.

MOURA, M. O. Matemática na Infância. In: MIGUEIS, M. R.; AZEVEDO, M. G. (Org.). Educação Matemática na Infância. Abordagens e desafios. Vila Nova de Gaia: Gailivro, 2007. p. 39-64.

MOURA, M. O. de. Pesquisa colaborativa: um foco na ação formadora. In: BARBOSA, R. L. L. (Org.). Trajetórias e perspectivas da formação de educadores. São Paulo: UNESP, 2004. p. 257-284.

MOURA, M. O. A formação matemática dos professores de Educação Infantil. In: Anais I Congresso Brasileiro de Etnomatemática, São Paulo, 2000.

MOURA, M. O.; SFORNI, M. S. F.; ARAÚJO, E. S. Objetivação e apropriação de conhecimentos da atividade orientadora de ensino. Revista Teoria e Prática da Educação, v. 14, n. 1, p. 39-50, 2011. Disponível em:

https://periodicos.uem.br/ojs/index.php/TeorPratEduc/article/view/15674. Acesso em: 31 mai. 2021.

MOURA, M. R. L. Reformas educacionais, Protagonismo Juvenil e Grêmio Estudantil: a produção do indivíduo resiliente. Germinal: Marxismo e Educação em Debate, v. 3, n. 1, p. 159, 2011. Disponível em:

https://periodicos.ufba.br/index.php/revistagerminal/article/view/9505. Acesso em: 31 mai. 2021.

NÓVOA, A. Tendências atuais na formação de professores: o modelo universitário e outras possibilidades de formação. In: Anais do Congresso Estadual Paulista sobre formação de educadores, Águas de Lindoia, 11, 2011.

PARO, V. H. Escritos sobre educação. São Paulo: Xamã, 2010.

PEREIRA, E. F. O jogo no ensino e aprendizagem de matemática. Universidade Federal do Recôncavo da Bahia, 2011.

PÉREZ GÓMEZ, A. A cultura escolar na sociedade neoliberal. Porto Alegre: Editora ArtMed, 2001.

POLIVANOVA, N. Particularidades da solução de um problema combinatório por estudantes em atuação de cooperação. In: GARNIER, C.; BEDNARZ, N.; ULANOVSKAYA, I. Após Vygotsky e Piaget: perspectivas social e construtivista. escolas russa e ocidental. Porto Alegre: Artes Médicas, 1996. p. 151-159. 
PRADO, E. P. A. Os textos impressos para o ensino dos números inteiros na visão de licenciandos em Matemática. Tese (doutorado) - Unicamp, Campinas, 2008.

RUBTSOV, V. A atividade de aprendizado e os problemas referentes à formação do pensamento teórico dos escolares. In: GARNIER, C.; BEDNARZ, N.; ULANOVSKAYA, I. Após Vygotsky e Piaget: perspectivas social e construtivista. escolas russa e ocidental. Porto Alegre: Artes Médicas, 1996.

SERRAZINA, L. A formação para o ensino da Matemática: Perspectivas futuras. In: SERRAZINA, L. (Org.). Cadernos de Formação de Professores - A formação para o ensino da matemática na educação pré-escolar e no $1^{\circ}$ ciclo do ensino básico. Porto: Porto Editora; INAFOP, 2002. v. 3.

SILVA, M. R. Conhecimento matemático e suas significações: professores de matemática em formação inicial no Clube de Matemática. Dissertação (Mestrado em Educação em Ciências e Matemática). Universidade Federal de Goiás, Goiás, 2019. Disponível em: http://repositorio.bc.ufg.br/tede/handle/tede/10060. Acesso em: 01 jun. 2021.

VIGOTSKI, L. S. A formação social da mente. São Paulo: Martins Fontes, 1991.

\section{APÊNDICE 1}

\section{AGRADECIMENTOS}

"Não se aplica."

\section{FINANCIAMENTO}

O presente trabalho foi realizado com apoio da Coordenação de Aperfeiçoamento de Pessoal de Nível Superior Brasil (CAPES) - Código de Financiamento 001.

\section{CONTRIBUIÇÕES DE AUTORIA}

Resumo/Abstract/Resumen: Mayline Regina Silva e Wellington Lima Cedro Introdução: Mayline Regina Silva e Wellington Lima Cedro Referencial teórico: Mayline Regina Silva e Wellington Lima Cedro Análise de dados: Mayline Regina Silva e Wellington Lima Cedro Discussão dos resultados: Mayline Regina Silva e Wellington Lima Cedro Conclusão e considerações finais: Mayline Regina Silva e Wellington Lima Cedro Referências: Mayline Regina Silva e Wellington Lima Cedro Revisão do manuscrito: Mayline Regina Silva e Wellington Lima Cedro Aprovação da versão final publicada: Mayline Regina Silva e Wellington Lima Cedro

\section{CONFLITOS DE INTERESSE}

Os autores declararam não haver nenhum conflito de interesse de ordem pessoal, comercial, acadêmico, político e financeiro referente a este manuscrito.

\section{DISPONIBILIDADE DE DADOS DE PESQUISA}

Os autores declaram que disponibilizarão, se forem solicitados, todos os dados publicados e não publicados, tais como videogravações, textos e transcrições relacionados à investigação.

\section{CONSENTIMENTO DE USO DE IMAGEM}

"Não se aplica." 
APROVAÇÃO DE COMITÊ DE ÉTICA EM PESQUISA

Informamos que o projeto investigativo referido neste artigo foi analisado e aprovado pelo Comitê de Ética, cujo número do CAAE é 86985018.0.0000.5083.

COMO CITAR - ABNT

SILVA, Mayline Regina.; CEDRO, Wellington Lima. Diálogos sobre o conhecimento matemático de um grupo de professores de matemática em formação inicial. REAMEC - Rede Amazônica de Educação em Ciências e Matemática. Cuiabá, v. 9, n. 2, e21040, maio-agosto, 2021. http://dx.doi.org/10.26571/reamec.v9i2.12002

\section{COMO CITAR - APA}

Silva, M. R.; Cedro, W. L. (2021). Diálogos sobre o conhecimento matemático de um grupo de professores de matemática em formação inicial. REAMEC - Rede Amazônica de Educação em Ciências e Matemática, 9(2), e21040. DOI: http://dx.doi.org/10.26571/reamec.v9i2.12002

\section{LICENÇA DE USO}

Licenciado sob a Licença Creative Commons Attribution-NonCommercial 4.0 International (CC BY-NC 4.0). Esta licença permite compartilhar, copiar, redistribuir o manuscrito em qualquer meio ou formato. Além disso, permite adaptar, remixar, transformar e construir sobre o material, desde que seja atribuído o devido crédito de autoria e publicação inicial neste periódico.

\section{DIREITOS AUTORAIS}

Os direitos autorais são mantidos pelos autores, os quais concedem à Revista REAMEC - Rede Amazônica de Educação em Ciências e Matemática - os direitos exclusivos de primeira publicação. Os autores não serão remunerados pela publicação de trabalhos neste periódico. Os autores têm autorização para assumir contratos adicionais separadamente, para distribuição não exclusiva da versão do trabalho publicada neste periódico (ex.: publicar em repositório institucional, em site pessoal, publicar uma tradução, ou como capítulo de livro), com reconhecimento de autoria e publicação inicial neste periódico. Os editores da Revista têm o direito de proceder a ajustes textuais e de adequação às normas da publicação.

\section{PUBLISHER}

Universidade Federal de Mato Grosso. Programa de Pós-graduação em Educação em Ciências e Matemática (PPGECEM) da Rede Amazônica de Educação em Ciências e Matemática (REAMEC). Publicação no Portal de Periódicos UFMT. As ideias expressadas neste artigo são de responsabilidade de seus autores, não representando, necessariamente, a opinião dos editores ou da referida universidade.

\section{EDITOR}

Dailson Evangelista Costa (D) $(-)$

\section{HISTÓRICO}

Submetido: 17 de março de 2021.

Aprovado: 23 de abril de 2021.

Publicado: 02 de junho de 2021. 